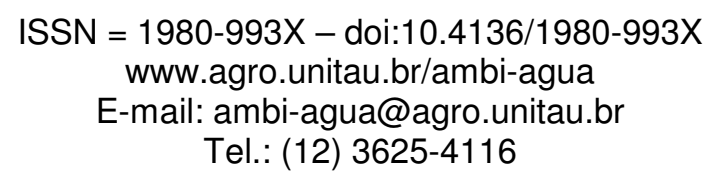

\title{
Influência do uso do solo na qualidade da água no bioma Cerrado: um estudo comparativo entre bacias hidrográficas no Estado de Goiás, Brasil
}

(doi:10.4136/ambi-agua.96)

\author{
Clarisse Guimarães Rabelo"; Manuel Eduardo Ferreira ${ }^{2}$; José Vicente Granato de \\ Araújo $^{3}$; Luis Fernando Stone ${ }^{4}$; Silvando Carlos da Silva ${ }^{4}$; Marisa Prado Gomes ${ }^{4}$ \\ ${ }^{1}$ Universidade Federal de Goiás / Programa de Mestrado em Engenharia do Meio Ambiente \\ E-mail: clarisserabelo1981@gmail.com \\ ${ }^{2}$ Universidade Federal de Goiás / Instituto de Estudos Socioambientais \\ E-mail: manuel@iesa.ufg.br \\ ${ }^{3}$ Universidade Federal de Goiás / Engenharia Civil \\ E-mail: jvgranato@yahoo.com.br \\ ${ }^{4}$ Empresa Brasileira de Pesquisa Agropecuária \\ E-mail: \{stone, silvando, marisa $@$ cnpaf.embrapa.br
}

\section{RESUMO}

Com base na hipótese de que a qualidade da água de uma bacia hidrográfica está diretamente relacionada com o grau de equilíbrio entre fatores naturais e antrópicos, buscouse neste artigo analisar os efeitos da conversão dos remanescentes de Cerrado sobre a manutenção e viabilidade ecológica das bacias hidrográficas. Para tanto, foram adotadas como área de estudo duas bacias de médio porte localizadas no Estado de Goiás (área representativa desse bioma), com características diferentes no que diz respeito aos aspectos físicos (solo, topografia e cobertura vegetal) e antrópicos (nível de degradação ambiental e índice de desenvolvimento econômico): (1) a bacia do Ribeirão João Leite, localizada no Centro-Sul Goiano (nível de antropização $=88 \%$ ); e (2) a bacia do Rio São Domingos, ao Norte do Estado (nível de antropização $=25 \%$ ). As análises químicas demonstram que a água na bacia do Rio São Domingos apresenta, de uma forma geral, melhor qualidade para o consumo humano e para a manutenção do ecossistema na região analisada, refletindo o elevado estado de conservação dessa bacia.

Palavras-chave: Análise espacial; degradação ambiental; recursos hídricos.

\section{Land use influence in the Cerrado biome water quality: a comparative study between watersheds in the Goiás State, Brazil}

\begin{abstract}
Based on the assumption that the water quality in a watershed is directly related to the degree of equilibrium between the natural and anthropic factors, in this paper we examined the effects of the land cover changes in areas of savanna (Cerrado biome) over the watersheds ecological viability (expressed here as Water Quality Index). Thus, we analyzed two middlesized basins located in the Goiás State (a representative area of this biome), with different characteristics regarding both the physical aspects (soil, topography and remnant vegetation) and human aspects (environmental degradation level and economic development index): (1) João Leite basin, located in the Center-South State (anthropic level $=88 \%$ ), and (2) São Domingos basin, in the Northern State (anthropic level $=25 \%$ ). Chemical analyses have indicated that the water in the São Domingos basin presents, in general, a better quality for
\end{abstract}


RABElo, C. G.; FERreirA, M. E.; ARAúJo, J. V. G.; STONE, L. F.; Silva, S. C.; GOMES, M. P. Influência do uso do solo na qualidade da água no bioma Cerrado: um estudo comparativo entre bacias hidrográficas no Estado de Goiás, Brasil. Ambi-Agua, Taubaté, v. 4, n. 2, p. 172-187, 2009. (doi:10.4136/ambiagua.96)

human consumption and for the ecosystem maintaining, reflecting the high conservation state of this basin as well.

Keywords: Spatial analysis; environmental degradation; water resources.

\section{INTRODUÇÃO}

A água é um recurso natural indispensável para a sustentação da biodiversidade, na produção de alimentos e para os ciclos naturais dos seres vivos. Por outro lado, ainda que com reconhecida importância ecológica, econômica e social, esse recurso tem se tornado escasso nos últimos anos, sobretudo nos grandes centros urbanos. Parte desse problema se deve à falta de planejamento e gestão das bacias hidrográficas, materializado no uso indiscriminado dos recursos hídricos, no desmatamento de nascentes e na poluição dos rios e lagos (Tundisi e Tundisi, 2005).

No Brasil, a região ocupada pelo bioma Cerrado é reconhecida como o "berço das águas", por abrigar nascentes de três importantes bacias hidrográficas da América do Sul (Araguaia/Tocantins, São Francisco e Bacia do Prata). Apesar dessa condição privilegiada, a qual lhe favorece o título de hotspot de biodiversidade no mundo (Myers et al., 2000), o Cerrado também está na lista dos ecossistemas ameaçados de extinção. Mapeamentos recentes (Sano et al., 2008a), baseados em informações extraídas de imagens de satélite (Landsat-TM), indicam uma taxa de conversão antrópica na ordem de $40 \%$ sobre a área original desse bioma (aproximadamente 2 milhões de $\mathrm{km}^{2}$ ), voltada para a prática da agricultura intensiva e pastagem. Soma-se a isso o fato de sua conservação ambiental não estar prevista, até o presente momento, na Constituição Federal, diferentemente do que ocorre com o bioma Amazônico.

Dentro desse contexto e com base na hipótese de que a qualidade da água de uma bacia hidrográfica está diretamente relacionada com o grau de equilíbrio entre fatores naturais e antrópicos (Von Sperling, 2005), o presente artigo visa analisar os impactos negativos provenientes da conversão dos remanescentes de Cerrado sobre a manutenção e viabilidade ecológica das bacias hidrográficas, buscando ao mesmo tempo evidenciar a relação entre uso do solo e qualidade da água.

Para tanto, foram adotadas como área de estudo duas bacias de médio porte (segundo classificação de Moraes, 1979 e Bonnet at al., 2008) localizadas no Estado de Goiás, uma área core e representativa do Cerrado (Ferreira et al., 2006; Miziara e Ferreira, 2008), com características diferentes no que diz respeito aos aspectos físicos (solos, topografia e cobertura vegetal nativa) e antrópicos (índices socioeconômicos e de degradação ambiental): (1) a bacia do Ribeirão João Leite, bastante antropizada, localizada no Centro-Sul Goiano e (2) a bacia do Rio São Domingos, ao norte do Estado, com grande parte de sua área ainda preservada.

\section{CARACTERIZAÇÃO DAS ÁREAS DE ESTUDO}

As bacias hidrográficas adotadas como áreas de estudo são as do Ribeirão João Leite (área de $767 \mathrm{~km}^{2}$ ) e do Rio São Domingos (área de $3955 \mathrm{~km}^{2}$ ), ambas no Estado de Goiás. A Figura 1 indica o posicionamento geográfico delas.

A bacia do Ribeirão João Leite coincide com a área parcial de sete municípios goianos: Anápolis, Goianápolis, Campo Limpo de Goiás, Goiânia, Nerópolis, Ouro Verde de Goiás e Terezópolis de Goiás. Trata-se de um manancial de importância estratégica, atualmente responsável por mais de 50\% do suprimento de água para a capital do Estado, a cidade de Goiânia. 
RABElO, C. G.; FERREIRA, M. E.; ARAÚJO, J. V. G.; STONE, L. F.; SILVA, S. C.; GOMES, M. P. Influência do uso do solo na qualidade da água no bioma Cerrado: um estudo comparativo entre bacias hidrográficas no Estado de Goiás, Brasil. Ambi-Agua, Taubaté, v. 4, n. 2, p. 172-187, 2009. (doi:10.4136/ambiagua.96)

Já a bacia do Rio São Domingos, na porção Norte-Nordeste do Estado, é composta por três municípios: Divinópolis de Goiás, Monte Alegre de Goiás e São Domingos. Localiza-se nela o Parque Estadual de Terra Ronca.

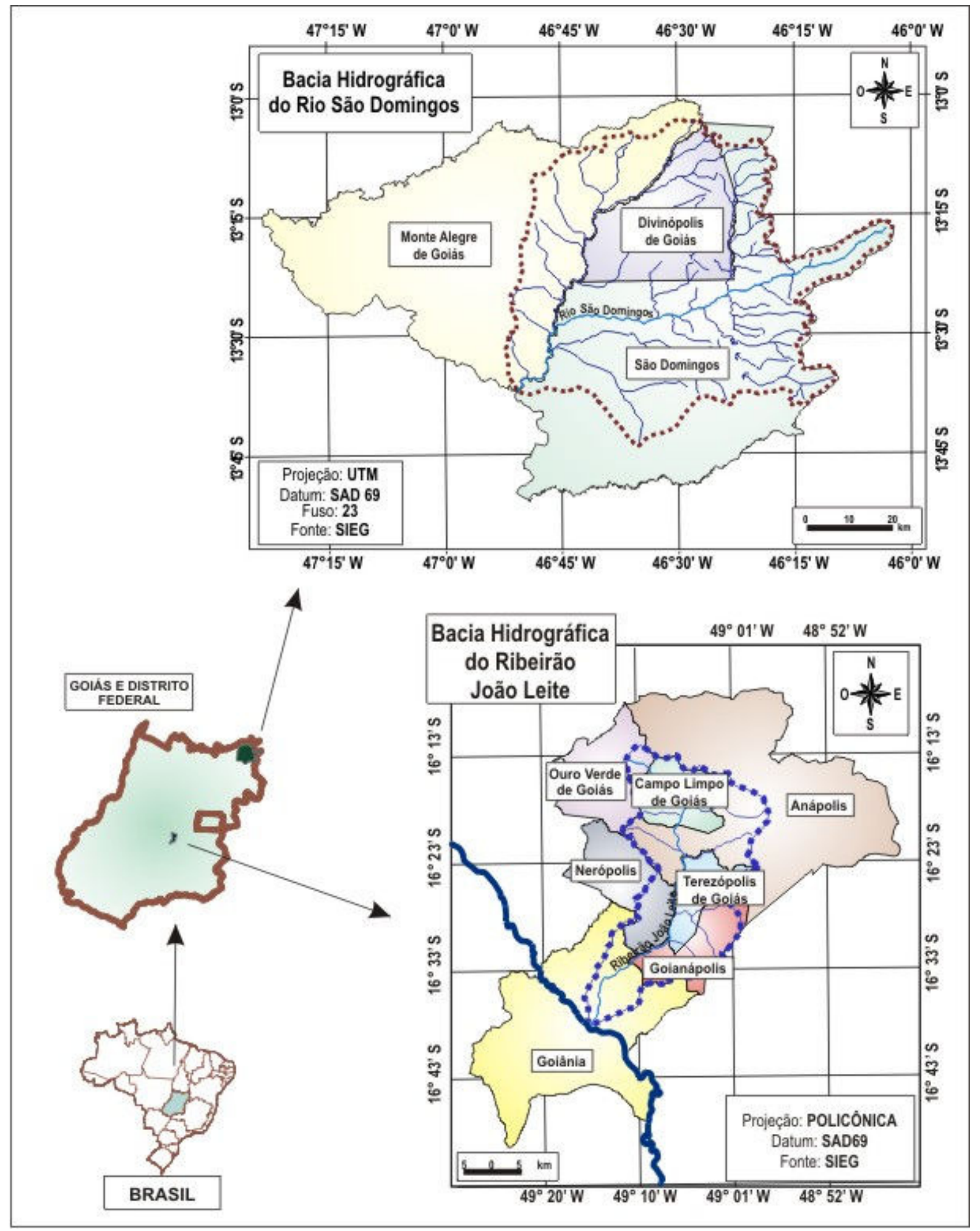

Figura 1. Localização das bacias hidrográficas do Rio São Domingos e do Ribeirão João Leite em Goiás.

Os municípios que compõem a bacia do Ribeirão João Leite têm aproximadamente 1.600.000 habitantes, basicamente concentrados em dois municípios: Goiânia (com 77\%) e 
RABElo, C. G.; FERreirA, M. E.; ARAúJo, J. V. G.; STONE, L. F.; Silva, S. C.; GOMES, M. P. Influência do uso do solo na qualidade da água no bioma Cerrado: um estudo comparativo entre bacias hidrográficas no Estado de Goiás, Brasil. Ambi-Agua, Taubaté, v. 4, n. 2, p. 172-187, 2009. (doi:10.4136/ambiagua.96)

Anápolis (com 20\%). Comparativamente, a população dos municípios da bacia do Rio São Domingos é estimada em cerca de 23.000 habitantes, sendo que $44 \%$ deles vivem no município de São Domingos, 32\%, em Monte Alegre de Goiás e os 24\% restantes em Divinópolis de Goiás. Na Figura 2, evidencia-se o contraste entre o número de habitantes das duas bacias.

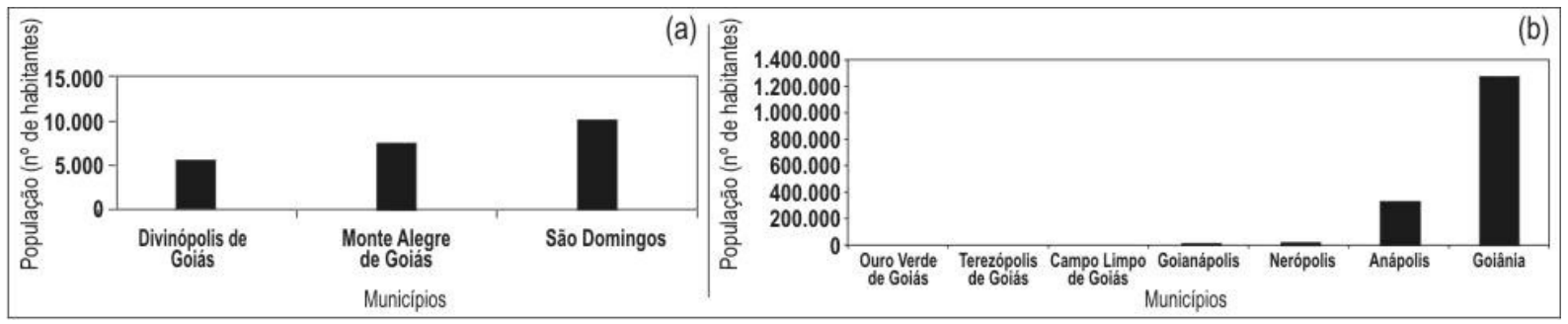

Figura 2. População dos municípios situados na bacia hidrográfica do Rio São Domingos (a) e do Ribeirão João Leite (b).

Fonte: SEPLAN-GO / SEPIN / Gerência de Estatística Socioeconômica (estimativa 2008 - IBGE).

De maneira geral, os municípios da bacia do Ribeirão João Leite mostram-se mais desenvolvidos que os da bacia do Rio São Domingos. O valor médio do Índice de Desenvolvimento Humano (IDH) dos municípios localizados na bacia do Ribeirão João Leite é de 0,75, variando entre 0,61 e 0,93. Goiânia tem o IDH-Municipal, Renda e Educação mais elevado, enquanto Goianápolis apresenta o menor IDH Municipal do grupo. Já os municípios da bacia do Rio São Domingos (ambiente mais preservado em termos ecológicos) apresentam um IDH mais baixo, com um valor médio de 0,64, mínimo de 0,53 e máximo de 0,75 (Figura $3)$.

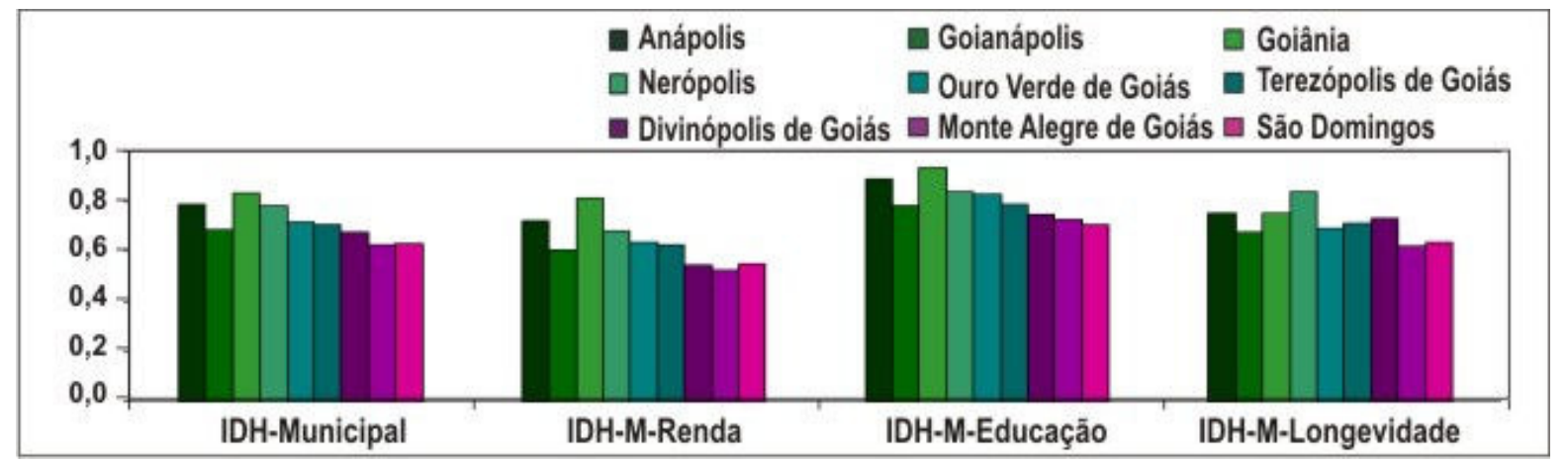

Figura 3. IDH-Municipal, Renda, Educação e Longevidade dos municípios situados nas bacias hidrográficas do Ribeirão João Leite e do Rio São Domingos. Fonte: Censo 2000, IBGE. Organização: SEPLAN-GO / SEPIN / Gerência de Estatística Socioeconômica.

Quanto às características físicas, as bacias do Ribeirão João Leite e do Rio São Domingos também são contrastantes. Em termos geomorfológicos, na bacia do Ribeirão João Leite há o predomínio de uma superfície regional de aplainamento desenvolvida sobre rochas précambrianas, com cotas entre 900 e 1100 metros, e dissecação forte (Latrubesse et al., 2005), com destaque para uma declividade acentuada nas bordas da porção norte e sudeste (Figura 4).

Já a bacia do Rio São Domingos também se localiza em uma superfície regional de aplainamento (porção Oeste), com cotas altimétricas mais baixas (entre 400 e 550 metros) e dissecação leve. Sua porção Leste se destaca como uma zona de erosão recuante, com dissecação muito forte (Latrubesse et al., 2005). Quanto à sua declividade (Figura 5), é caracterizada por uma topografia mais suave (principalmente na porção Oeste), o que, de acordo com Guerra (2003), favorece a infiltração e a recarga dos mananciais. 
RABElO, C. G.; FERREIRA, M. E.; ARAÚJO, J. V. G.; STONE, L. F.; SILVA, S. C.; GOMES, M. P. Influência do uso do solo na qualidade da água no bioma Cerrado: um estudo comparativo entre bacias hidrográficas no Estado de Goiás, Brasil. Ambi-Agua, Taubaté, v. 4, n. 2, p. 172-187, 2009. (doi:10.4136/ambiagua.96)

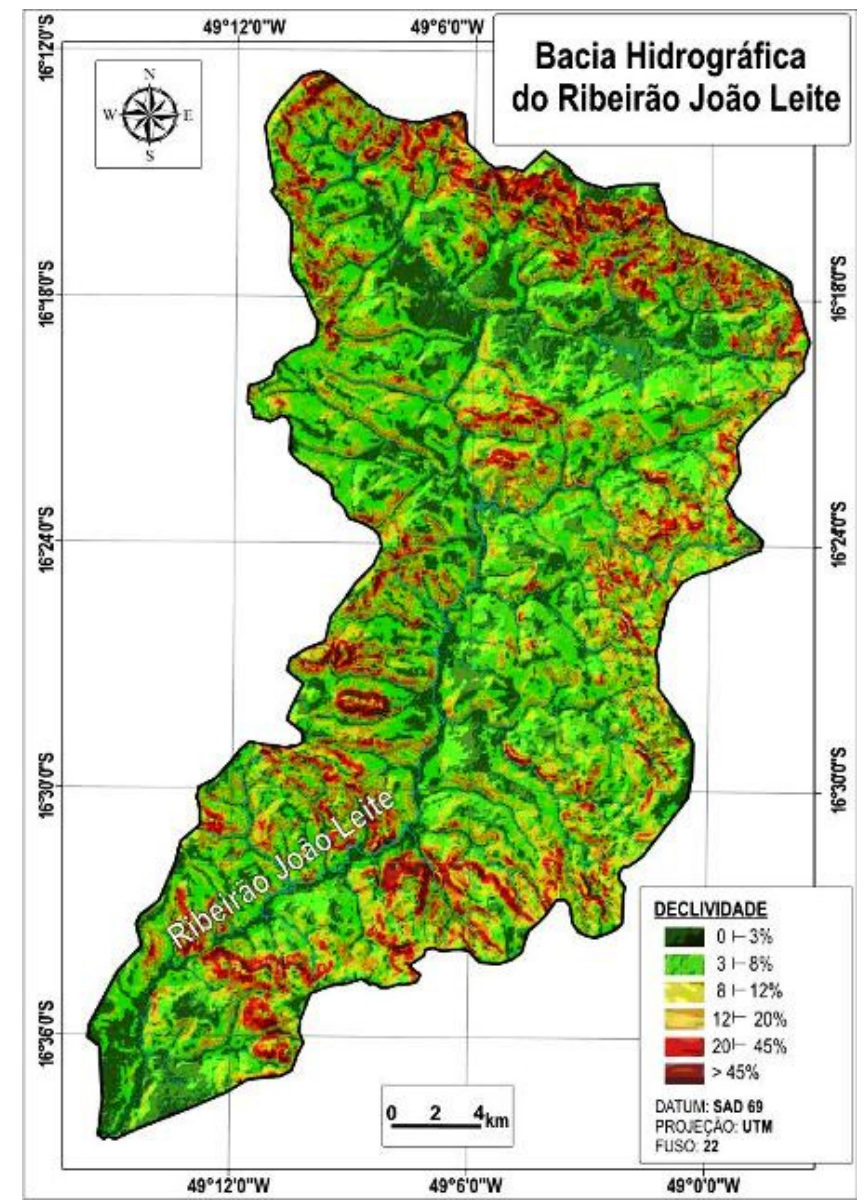

Figura 4. Mapa clinográfico da bacia hidrográfica do Ribeirão João Leite. Fonte: EMBRAPA (2009).

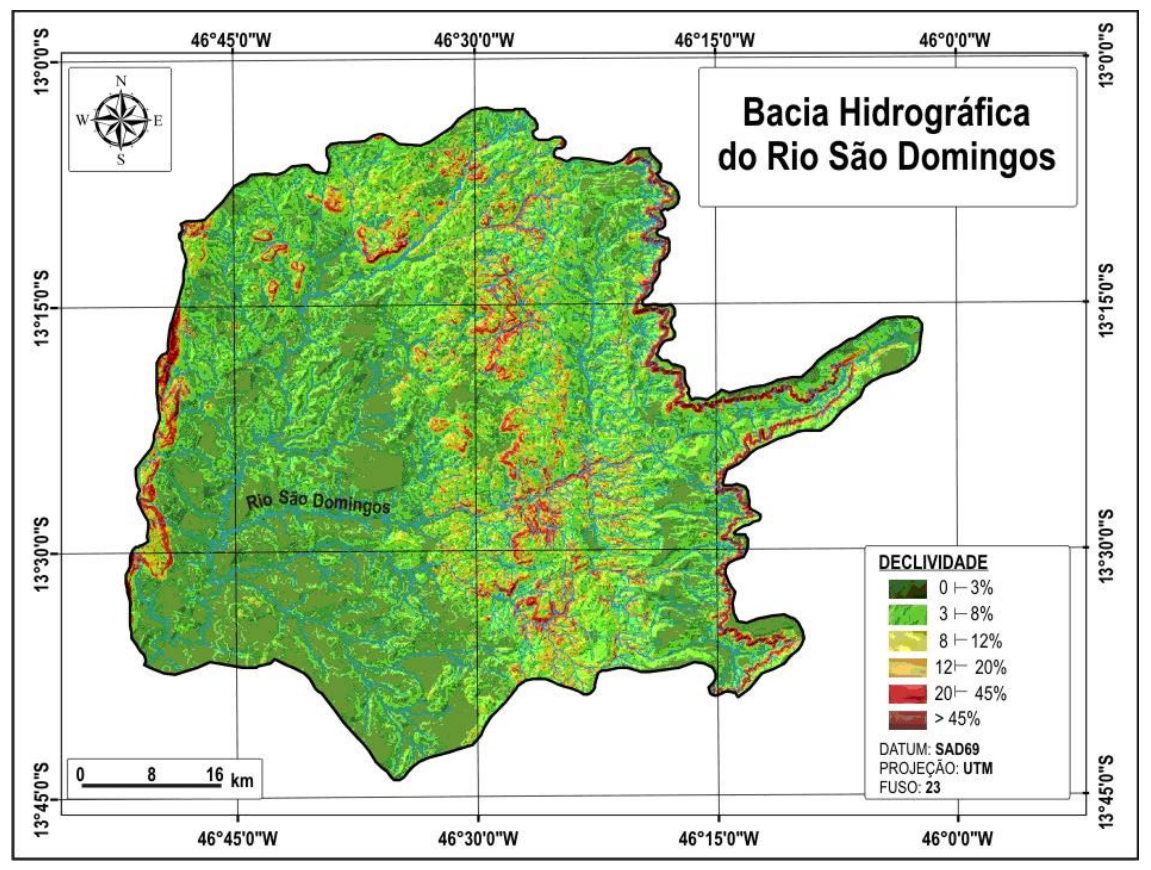

Figura 5. Mapa clinográfico da bacia hidrográfica do Rio São Domingos. Fonte: EMBRAPA (2009). 
RABElo, C. G.; FERreirA, M. E.; ARAúJo, J. V. G.; STONE, L. F.; Silva, S. C.; GOMES, M. P. Influência do uso do solo na qualidade da água no bioma Cerrado: um estudo comparativo entre bacias hidrográficas no Estado de Goiás, Brasil. Ambi-Agua, Taubaté, v. 4, n. 2, p. 172-187, 2009. (doi:10.4136/ambiagua.96)

Com menção aos solos, na bacia do Ribeirão João Leite há o predomínio de Latossolos, seguidos pela associação de Argissolos/Nitossolos (Figura 6), comumente utilizados para prática da agricultura. No caso dos Latossolos, eles geralmente ocorrem em áreas de relevo adequado ao uso de maquinários; já a associação Argissolos/Nitossolos, embora normalmente presente em áreas de relevo mais acidentado, é dotada de maior fertilidade natural e boa capacidade de retenção de água, o que, de acordo com Sano et al. (2008b), os torna indicados para pequenos agricultores e pecuaristas.

Já na bacia do Rio São Domingos (Figura 7), há uma maior ocorrência de Neossolos e Cambissolos, muito susceptíveis à erosão e, portanto, de baixa aptidão agrícola (Sano et al., 2008b).

Assim, as características físicas de cada bacia apresentam uma clara relação com o atual estágio de ocupação evidenciado neste estudo. A bacia do Ribeirão João Leite é amplamente utilizada para agricultura e pecuária, sendo o processo de urbanização mais intenso nessa bacia do que na bacia do Rio São Domingos (Figuras 6 e 8). Especificamente na bacia do Ribeirão João Leite, observa-se que as áreas destinadas às culturas anuais coincidem com a ocorrência de Latossolos, enquanto que as áreas de pastagem relacionam-se fortemente com a presença da associação Nitossolos/Argissolos. Por outro lado, na bacia do Rio São Domingos, o predomínio de remanescentes de Cerrado, juntamente com a ocorrência de pastagens nativas, vem garantido certa preservação ambiental, com o uso da terra em geral associado às áreas de relevo mais suave e solos de baixa aptidão agrícola.

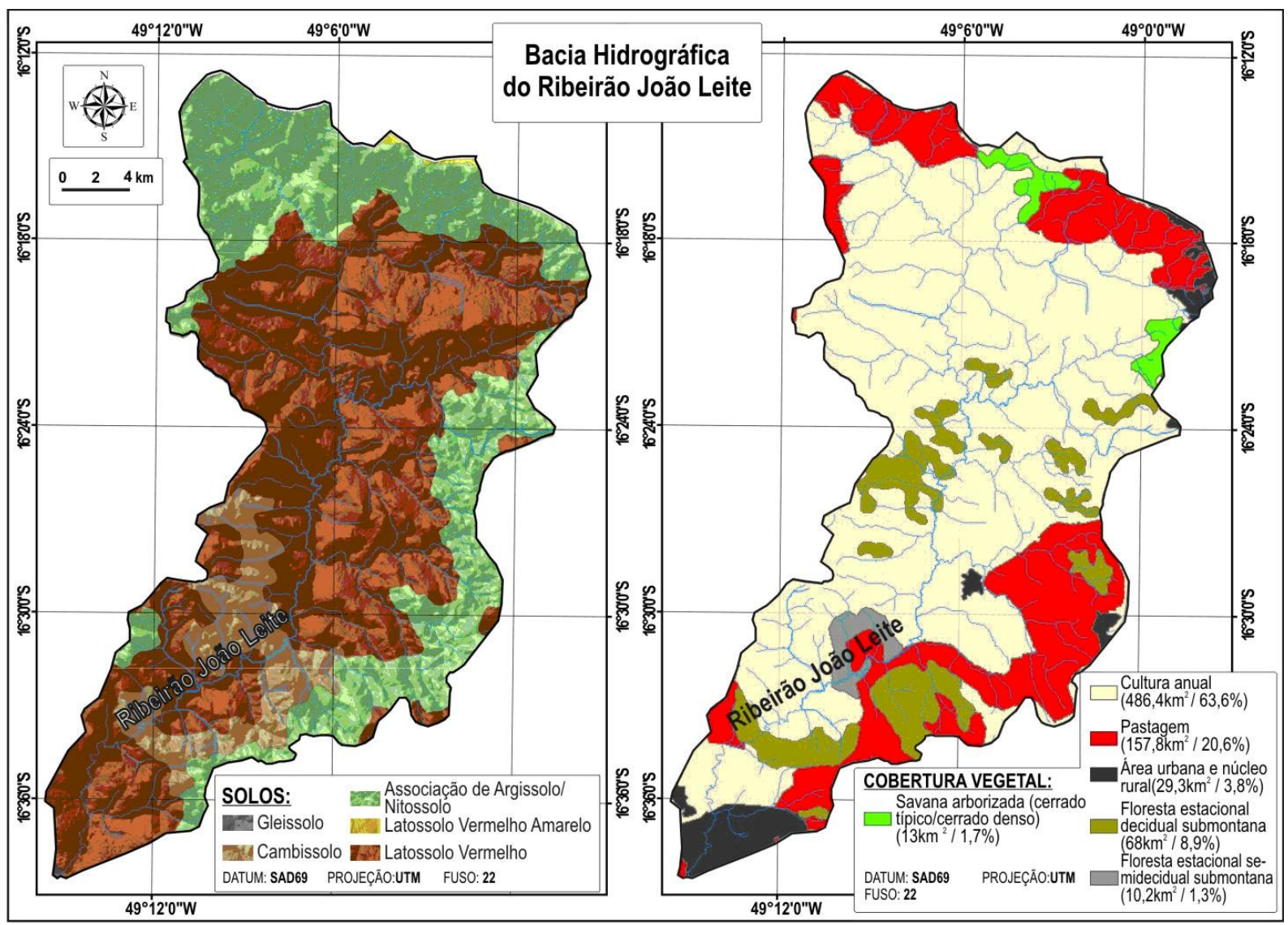

Figura 6. Mapa de solos e de cobertura vegetal, uso e ocupação do solo em 2002 da bacia hidrográfica do Ribeirão João Leite. Fontes: SIEG (2008) e PROBIO (2008). 
RABElO, C. G.; FERREIRA, M. E.; ARAÚJO, J. V. G.; STONE, L. F.; SILVA, S. C.; GOMES, M. P. Influência do uso do solo na qualidade da água no bioma Cerrado: um estudo comparativo entre bacias hidrográficas no Estado de Goiás, Brasil. Ambi-Agua, Taubaté, v. 4, n. 2, p. 172-187, 2009. (doi:10.4136/ambiagua.96)

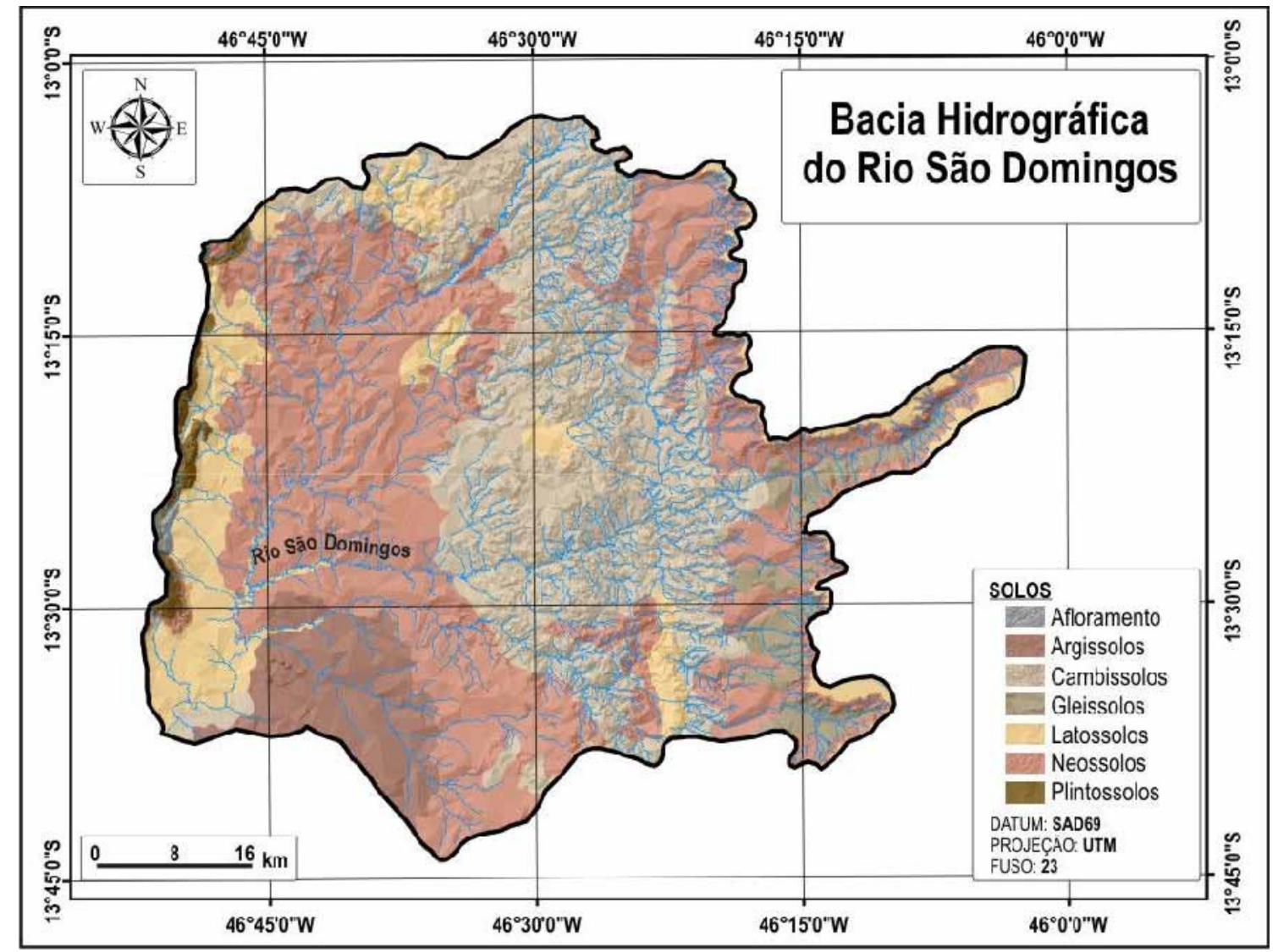

Figura 7. Mapa de solos da bacia hidrográfica do Rio São Domingos. Fonte: SIEG (2008).

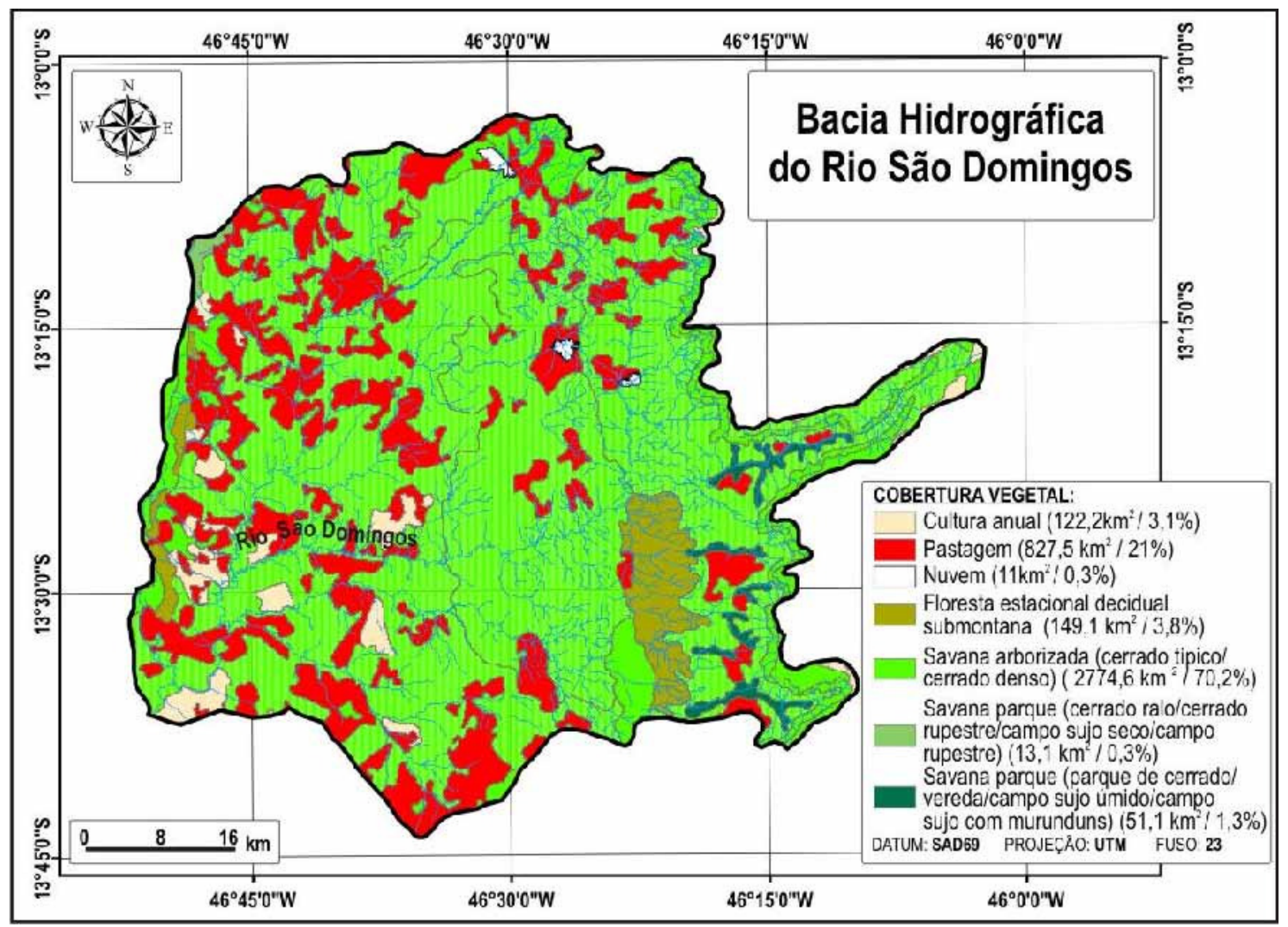

Figura 8. Mapa de cobertura vegetal e uso e ocupação do solo em 2002 da bacia hidrográfica do Rio São Domingos. Fonte: PROBIO (2008). 
RABElo, C. G.; FERreirA, M. E.; ARAúJo, J. V. G.; STONE, L. F.; Silva, S. C.; GOMES, M. P. Influência do uso do solo na qualidade da água no bioma Cerrado: um estudo comparativo entre bacias hidrográficas no Estado de Goiás, Brasil. Ambi-Agua, Taubaté, v. 4, n. 2, p. 172-187, 2009. (doi:10.4136/ambiagua.96)

\section{MATERIAIS E MÉTODOS}

A etapa inicial deste trabalho diz respeito à organização de bases cartográficas para cada uma das bacias hidrográficas descritas, contendo:

- Imagens Landsat-ETM (resolução espacial de 30 metros), obtidas no portal de dados Earth Science Data Interface (ESDI, 2008) - projeto Geocover - para as seguintes órbitas/ponto: 222/071 (Bacia do Ribeirão João Leite), referente ao mês de abril de 2000, e 220/069 (Bacia do Rio São Domingos), duas cenas, referentes aos meses de junho e agosto de 2001.

- Modelos Digitais de Elevação (formato GEOTIFF, resolução espacial de 90m) originários da missão de mapeamento do relevo terrestre de toda a Terra, intitulada Shuttle Radar Topography Mission (SRTM), obtidos do portal da Embrapa Monitoramento por Satélite (Embrapa, 2009).

- Dados vetoriais (formato shapefile) provenientes do portal de dados do Sistema Estadual de Estatística e de Informações Geográficas de Goiás (SIEG, 2008), abrangendo os seguintes temas: solos (escala 1:250.000), geomorfologia (escala 1:500.000) e bacias hidrográficas (escala 1:250.000).

- Malha hidrográfica do Estado de Goiás (formato shapefile), obtida junto ao portal de dados da Agência Rural de Goiás (2008), na escala 1:100.000.

- Mapa de remanescentes de Cerrado (escala 1:250.000), proveniente do Projeto de Conservação e Utilização Sustentável da Diversidade Biológica Brasileira (PROBIO, 2008).

- Dados de análises qualitativas de água bruta, referente aos pontos de monitoramento da Agência Ambiental de Goiás (2008) nas bacias do Ribeirão João Leite e do Rio São Domingos.

As bases cartográficas foram reprojetadas para a projeção UTM (Universal Transversa de Mercator), datum horizontal SAD 69, fuso 22 para a bacia do Ribeirão João Leite e fuso 23 para a bacia do Rio São Domingos. Num segundo momento, alguns procedimentos foram realizados em ambiente de Sistema de Informações Geográficas, tais como:

- Edição das drenagens, tendo como referência as imagens Landsat-ETM;

- Geração de zona tampão (ou buffer) de 100 metros ao longo das drenagens (Áreas de Preservação Permanente);

- Intersecção da zona ripária com o mapa de remanescentes de vegetação, visando identificar o uso da terra nas áreas próximas aos cursos de drenagens; e

- Cálculo de área para cada tipo de uso do solo nas bacias.

Por fim, foi calculado o Índice de Qualidade de Água (IQA) para os pontos monitorados pela Agência Ambiental de Goiás. O cálculo do IQA foi realizado tendo como base a metodologia adaptada e desenvolvida pela Companhia de Tecnologia de Saneamento Ambiental do Estado de São Paulo (CETESB). Assim, o IQA resulta do produto ponderado das qualidades de água correspondentes aos parâmetros: temperatura da amostra, $\mathrm{pH}$, oxigênio dissolvido, demanda bioquímica de oxigênio ( 5 dias, $\left.20^{\circ} \mathrm{C}\right)$, coliformes fecais, nitrogênio total, fósforo total, resíduos totais e turbidez (Equação 1).

$$
I Q A=\prod_{i=1}^{n} q_{i}^{{ }^{w_{i}}}
$$

em que:

$q_{i}$ : qualidade do i-ésimo parâmetro. É obtida de uma curva média de variação da qualidade. Tais curvas são ilustradas na Figura 9.

$W_{i}$ : peso correspondente ao i-ésimo parâmetro (entre 0 e 1), atribuído em função da sua importância para a conformação da qualidade, o somatório de todos os pesos deve ser igual a 1. 
RABElo, C. G.; FERreirA, M. E.; ARAúJo, J. V. G.; STONE, L. F.; Silva, S. C.; GOMES, M. P. Influência do uso do solo na qualidade da água no bioma Cerrado: um estudo comparativo entre bacias hidrográficas no Estado de Goiás, Brasil. Ambi-Agua, Taubaté, v. 4, n. 2, p. 172-187, 2009. (doi:10.4136/ambiagua.96)
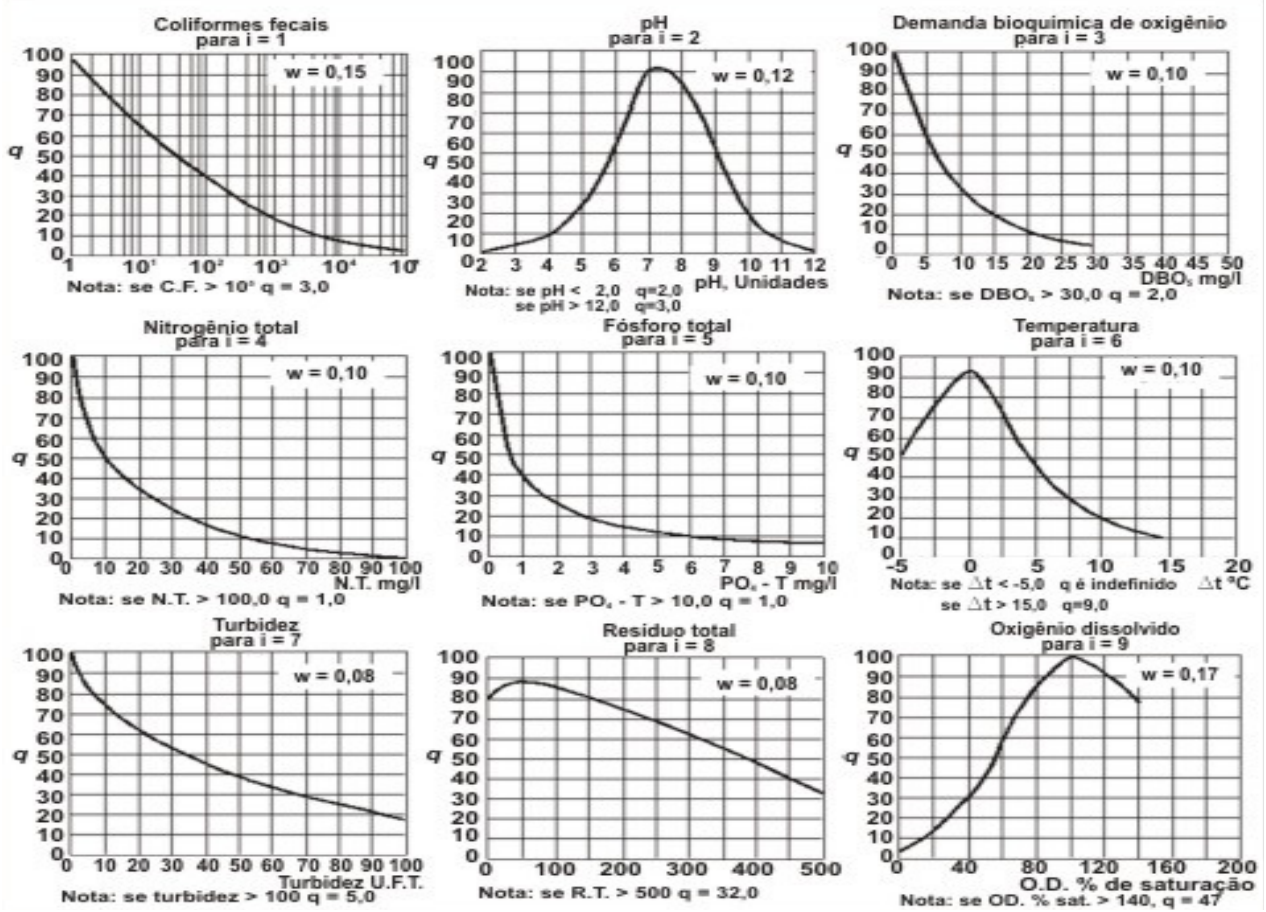

Figura 9. Curvas de variação dos parâmetros do IQA. Fonte: CETESB (2009).

Tabela 1. Pesos utilizados para cálculo de IQA, com oito parâmetros.

\begin{tabular}{lcccccccccc}
\hline Parâmetros & Peso original $(\boldsymbol{w})$ & \multicolumn{8}{c}{ Peso recalculado para IQA com oito parâmetros } \\
Temperatura & 0,10 & ----- & 0,11 & 0,11 & 0,11 & 0,11 & 0,11 & 0,12 & 0,12 & 0,11 \\
\hline $\mathrm{pH}$ & 0,12 & 0,13 & ----- & 0,13 & 0,13 & 0,13 & 0,13 & 0,14 & 0,14 & 0,13 \\
Turbidez & 0,08 & 0,09 & 0,09 & ----- & 0,09 & 0,09 & 0,09 & 0,10 & 0,09 & 0,09 \\
DBO & 0,10 & 0,11 & 0,11 & 0,11 & ----- & 0,11 & 0,11 & 0,12 & 0,12 & 0,11 \\
Fosfato & 0,10 & 0,11 & 0,11 & 0,11 & 0,11 & ----- & 0,11 & 0,12 & 0,12 & 0,11 \\
Nitrogênio total & 0,10 & 0,11 & 0,11 & 0,11 & 0,11 & 0,11 & ----- & 0,12 & 0,12 & 0,11 \\
OD & 0,17 & 0,19 & 0,19 & 0,18 & 0,19 & 0,19 & 0,19 & ----- & 0,20 & 0,18 \\
Coliformes fecais & 0,15 & 0,17 & 0,17 & 0,16 & 0,17 & 0,17 & 0,17 & 0,18 & ----- & 0,16 \\
Resíduos totais & 0,08 & 0,09 & 0,09 & 0,09 & 0,09 & 0,09 & 0,09 & 0,10 & 0,09 & ----- \\
\hline Total & 1,00 & 1,00 & 1,00 & 1,00 & 1,00 & 1,00 & 1,00 & 1,00 & 1,00 & 1,00 \\
\hline
\end{tabular}

Devido à falta de resultados para várias análises de parâmetros qualitativos da água, em alguns casos o IQA foi calculado utilizando-se oito parâmetros. Os pesos utilizados para o cálculo do IQA com os valores originais e recalculados encontram-se apresentados na Tabela 1. De posse dos pontos de coleta de água com os resultados de IQA, indicando (qualidade variando de 0 a 100), estes foram sobrepostos aos mapas de cobertura vegetal nas zonas ripárias, para ambas as bacias, visando analisar a relação entre uso do solo e a qualidade da água.

\section{RESULTADOS E DISCUSSÃO}

A bacia do Ribeirão João Leite, com um avançado estágio de conversão antrópica, apresenta cerca de $88 \%$ de sua área utilizada em agricultura e pastagem, enquanto a bacia do Rio São Domingos, numa condição inversa, apresenta apenas $25 \%$ de sua área convertida em tais classes de uso da terra. Nessas condições, e confirmando a nossa hipótese, a qualidade da 
água encontrada na primeira bacia foi inferior a da segunda, de acordo com as análises qualitativas da água bruta realizadas pela Agência Ambiental de Goiás (Figura 10).

De uma maneira geral, observa-se que os resultados das análises da água do Rio São Domingos encontram-se dentro dos valores permitidos pela Resolução 357 de 2005 do Conselho Nacional do Meio Ambiente (CONAMA) para rios de classe 2 (os valores de referência para a qualidade da água encontram-se listados na Tabela 2), com exceção para quatro parâmetros: valores de DBO e Fosfato acima do máximo permitido, e valores de pH e de oxigênio dissolvido menores que o mínimo admitido por essa Resolução.

Já no Ribeirão João Leite, foram encontrados resultados acima do permitido em sete parâmetros: Turbidez, DBO, Nitrato, Resíduos totais, Fosfato, Nitrogênio amoniacal e Coliformes fecais. Além disso, em alguns pontos, os três últimos parâmetros foram encontrados em concentrações muito elevadas. Em algumas análises, a quantidade de oxigênio dissolvido também foi menor que o permitido.

DBO e Resíduos totais elevados indicam alta concentração de matéria orgânica, desaconselhável para os ambientes de rios e lagos, pois desencadeiam uma proliferação de micro-organismos decompositores. Esses micro-organismos, por sua vez, por estarem em maior quantidade, consomem mais oxigênio dissolvido, excedendo o limite do ambiente e, assim, colocando em risco a vida aquática em questão. Além disso, a presença excessiva de resíduos implica aumento da turbidez da água, o que impede a passagem adequada de luz solar. Como resultado, tem-se o processo de fotossíntese prejudicado, uma menor produção de oxigênio e a proliferação de organismos anaeróbios. Valores elevados de coliformes fecais sugerem contaminação da água por esgoto de origem doméstica. Fosfato e Nitrogênio, em concentrações acima da permitida, são indicativos de adubações, minerais ou orgânicas, que provavelmente foram carreadas para o rio por erosão hídrica (Von Sperling, 2005).

Os resultados do IQA obtidos para cada uma das bacias estudadas fornecem um claro entendimento de que quanto maior o nível de preservação da bacia, melhor a qualidade de sua água. Na bacia do Ribeirão João Leite, por exemplo, o menor valor de IQA foi 36 e o maior foi 68 (com média de 49). Já na bacia do rio São Domingos, o IQA variou entre 55 e 70 (com média de 62). Além do fator "uso da terra" (i.e., áreas empregadas na agricultura ou pastagem), avaliado neste estudo, outros fatores (não abordados em profundidade por este artigo) podem contribuir para as diferenças na qualidade geral da água (IQA), tais como as tecnologias de plantios adotadas nas regiões em análise, bem como os aspectos do relevo. A tecnologia empregada está relacionada com o surgimento ou não de erosões, ou mesmo no volume de defensivos agrícolas, por exemplo. Especificamente em relação ao relevo, as áreas mais declivosas (ou planas) vão contribuir diretamente com a intensidade da descarga hídrica desses rios, ou mesmo no escoamento superficial da água, proveniente de áreas já ocupadas por atividades antrópicas.

No Ribeirão João Leite, o IQA médio do ponto "RMP PT5" foi de 52,5, e de 48 nos pontos "RMP PT7" e "RMP PT8". Assim, observa-se que a água de melhor qualidade do Ribeirão João Leite foi encontrada no ponto de captação da água para a metrópole de Goiânia, possivelmente devido à existência de uma Área de Preservação Ambiental nas proximidades (Parque Estadual Altamira de Moura Pacheco). No Rio São Domingos, o IQA médio encontrado para os pontos de 1 a 5 (PT1, PT2, PT3, PT4 e PT5) foram respectivamente 61, $63,3,65,8,59$ e 55 (valores que indicam água de boa qualidade).

Nas Figuras 11 e 12, é possível observar, para cada uma das bacias, os pontos de monitoramento da Agência Ambiental de Goiás, os resultados do IQA para cada ponto e o mapa de uso do solo nas Áreas de Preservação Permanente ao longo das drenagens (100 metros). 
RABElO, C. G.; FERREIRA, M. E.; ARAÚJO, J. V. G.; STONE, L. F.; SILVA, S. C.; GOMES, M. P. Influência do uso do solo na qualidade da água no bioma Cerrado: um estudo comparativo entre bacias hidrográficas no Estado de Goiás, Brasil. Ambi-Agua, Taubaté, v. 4, n. 2, p. 172-187, 2009. (doi:10.4136/ambiagua.96)

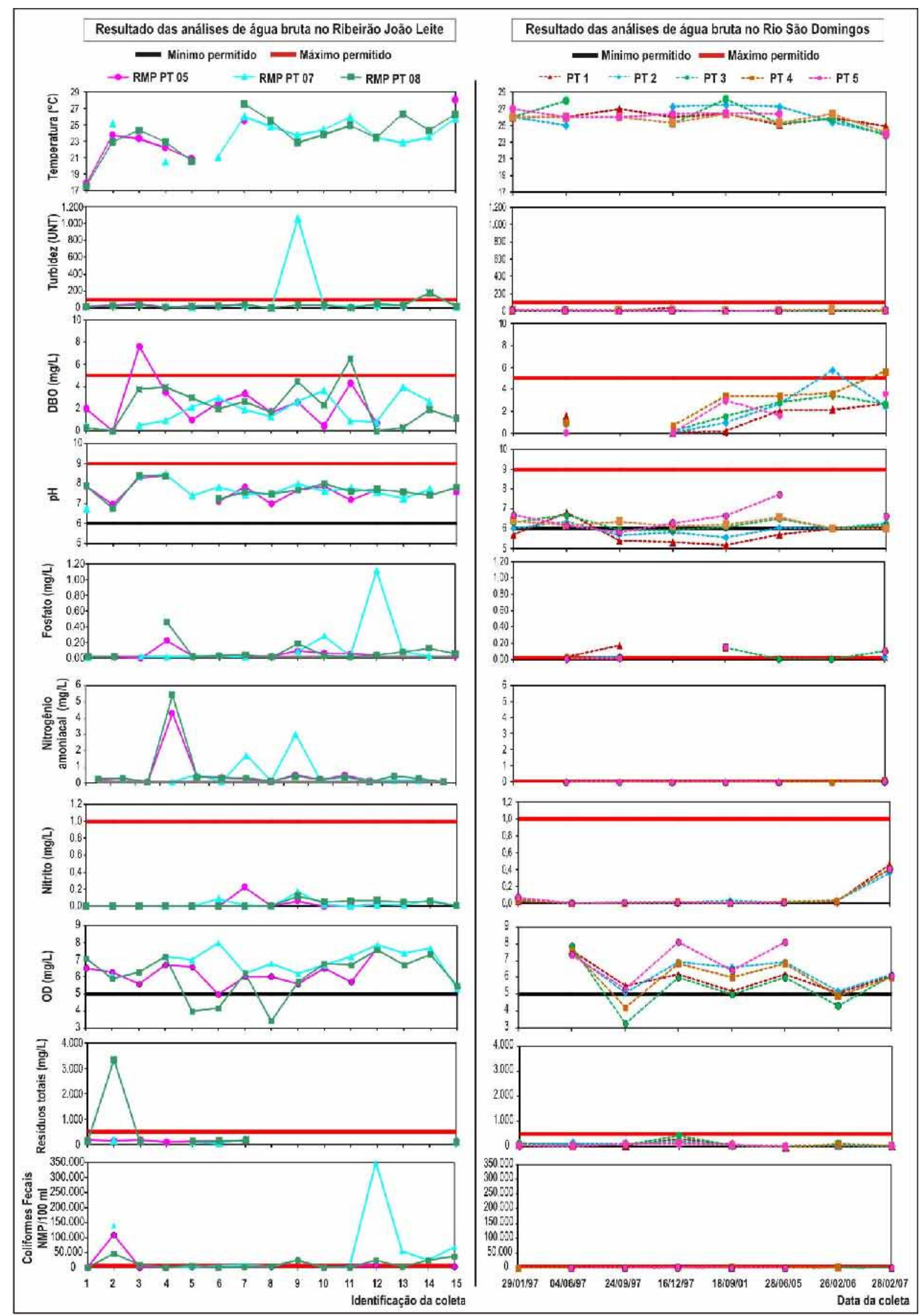

Figura 10. Resultado das análises qualitativas da água bruta do Ribeirão João Leite e do Rio São Domingos. Fonte: Agência Ambiental de Goiás (2008). As datas referentes às coletas na bacia do Ribeirão João Leite encontram-se na Figura 12. 
RABElO, C. G.; FERREIRA, M. E.; ARAÚJO, J. V. G.; STONE, L. F.; SILVA, S. C.; GOMES, M. P. Influência do uso do solo na qualidade da água no bioma Cerrado: um estudo comparativo entre bacias hidrográficas no Estado de Goiás, Brasil. Ambi-Agua, Taubaté, v. 4, n. 2, p. 172-187, 2009. (doi:10.4136/ambiagua.96)

Tabela 2. Padrões de qualidade da água. Fonte: CONAMA (Brasil, 2005).

\begin{tabular}{l|c|c}
\hline Parâmetros & Unidades & Valores permitidos (rios classe 2) \\
\hline Oxigênio dissolvido & $\mathrm{mg} / \mathrm{L}$ & $\geq 5$ \\
DBO & $\mathrm{mg} / \mathrm{L}$ & $\leq 5$ \\
Resíduos totais & $\mathrm{mg} / \mathrm{L}$ & 500 \\
Turbidez & $\mathrm{UNT}$ & $\leq 100$ \\
$\mathrm{pH}$ & - & $6 \mathrm{a} 9$ \\
Fósforo total & $\mathrm{mg} / \mathrm{L}$ & 0,025 \\
Nitrato & $\mathrm{mg} / \mathrm{L}$ & 10 \\
Nitrito & $\mathrm{mg} / \mathrm{L}$ & 1 \\
Íon amônio & $\mathrm{mg} / \mathrm{L}$ & - \\
Amônia & $\mathrm{mg} / \mathrm{L}$ & $\leq 5.000$ \\
Coliformes fecais & $\mathrm{NMP} / 100 \mathrm{ml}$ & \\
\hline
\end{tabular}

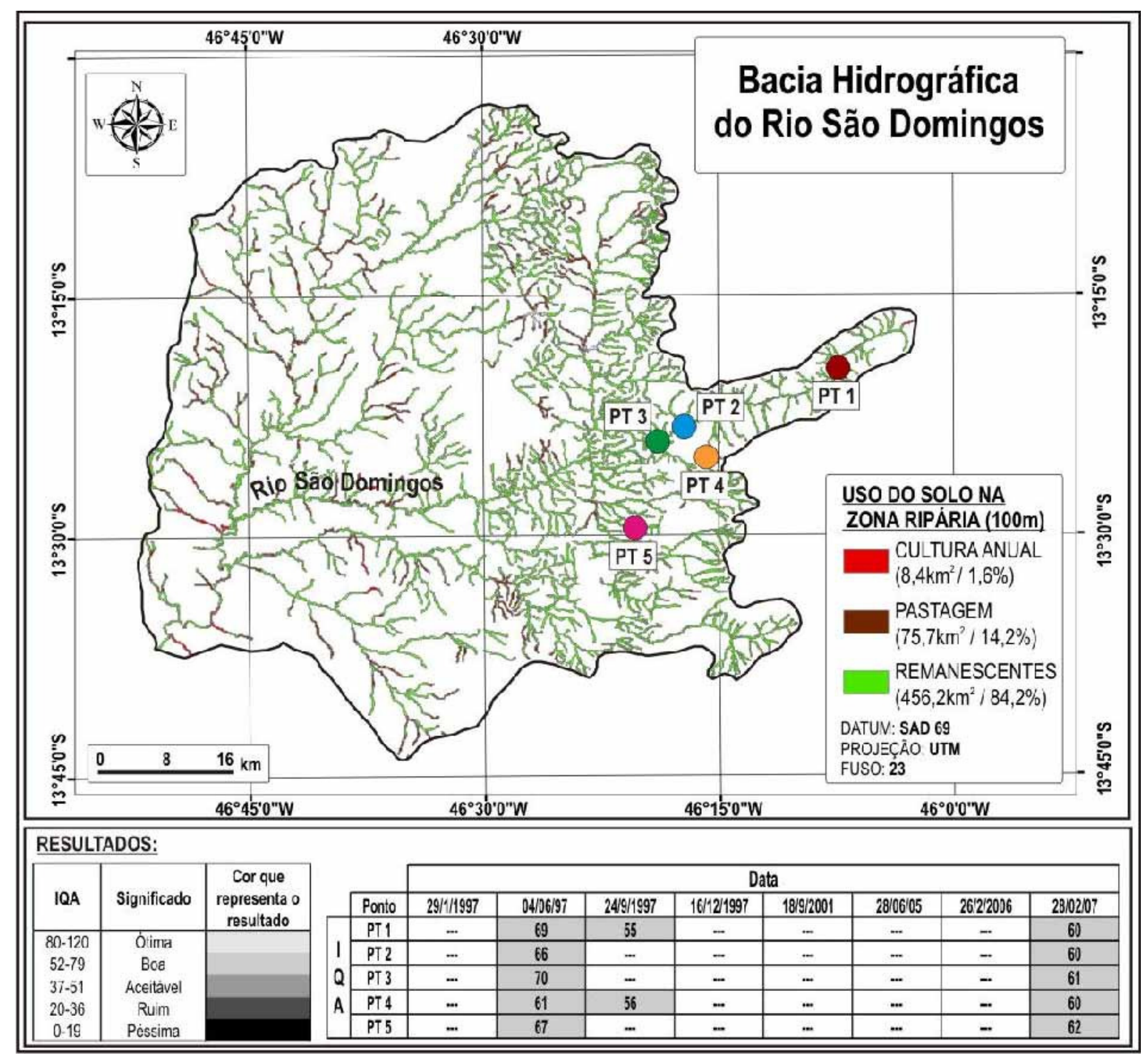

Figura 11. Pontos de monitoramento da Agência Ambiental de Goiás na bacia hidrográfica do Rio São Domingos, com destaque para o uso do solo nas zonas ripárias $(100 \mathrm{~m})$ e o respectivo resultado do IQA. 
RABElO, C. G.; FERREIRA, M. E.; ARAÚJO, J. V. G.; STONE, L. F.; SILVA, S. C.; GOMES, M. P. Influência do uso do solo na qualidade da água no bioma Cerrado: um estudo comparativo entre bacias hidrográficas no Estado de Goiás, Brasil. Ambi-Agua, Taubaté, v. 4, n. 2, p. 172-187, 2009. (doi:10.4136/ambiagua.96)

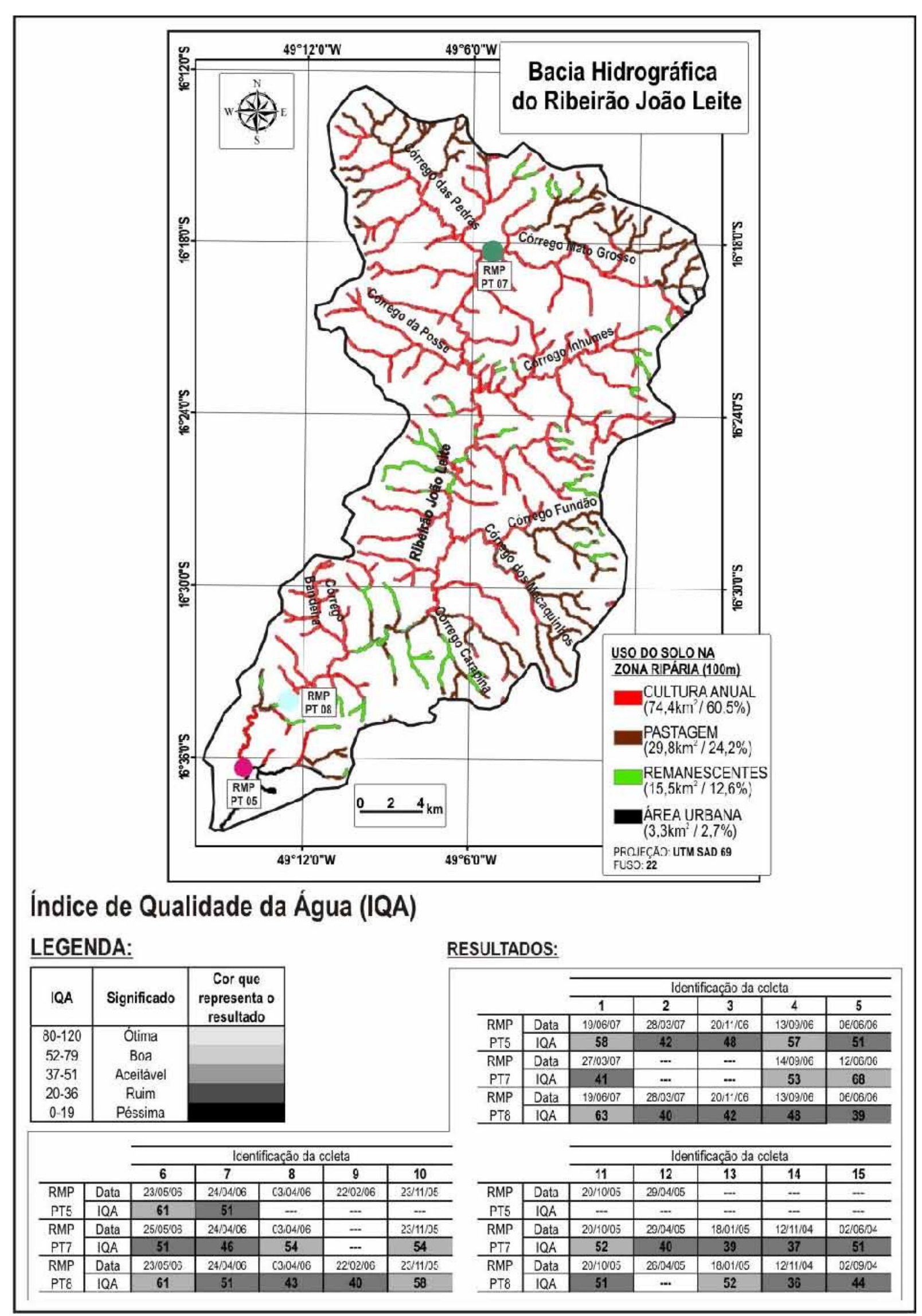

Figura 12. Pontos de monitoramento da Agência Ambiental de Goiás na bacia hidrográfica do Ribeirão João Leite, com destaque para o uso do solo nas zonas ripárias $(100 \mathrm{~m})$ e o respectivo resultado do IQA. 


\section{CONSIDERAÇÕES FINAIS}

As bacias hidrográficas do Ribeirão João Leite e do Rio São Domingos apresentam diferenças significativas, tanto em termos fisiográficos (incluindo a cobertura vegetal nativa, solos e relevos) quanto em níveis de antropismo, incluindo diferentes classes de uso da terra (agricultura, pastagens e áreas urbanas). Assim, e conforme evidenciado pelos resultados apresentados, foi possível observar o impacto do uso da terra intenso (e muitas vezes sem planejamento) sobre a qualidade da água.

Especificamente na bacia hidrográfica do Ribeirão João Leite, a qual se apresenta atualmente com um cenário de conservação seriamente comprometido (com apenas $12 \%$ de Cerrado nativo preservado), torna-se prioritária a preservação da vegetação nativa (principalmente ao longo dos rios e das nascentes) e a mitigação de atividades poluentes próximas aos mananciais (tal como a reciclagem e/ou o tratamento de efluentes, antes de seu descarte final na natureza).

Políticas de desenvolvimento sustentável e mecanismos econômicos para a valoração ambiental (Igliori et al., 2007; Neder e Silva, 2004; Chomitz, 2004) vêm sendo adotadas gradativamente no Estado de Goiás (assim como em alguns outros estados da federação), visando à manutenção de serviços ecológicos no Cerrado, tais como a água e a vegetação nativa (Ferreira et al., 2009; Novaes et al., 2008). Assim, a adoção de certificações especiais e a redução de certos impostos sobre a produção agrícola (ex. ICMS Ecológico) são exemplos de políticas simples e eficientes, capazes de evitar ou reduzir a degradação de áreas ainda conservadas.

Estudos complementares, investigando a relação entre a adoção de práticas conservacionistas com a qualidade da água, ainda se fazem necessários, tais como a análise de sub-regiões no Cerrado, cuja manutencão de reservas legais junto às áreas de nascentes seja de fato realizada. Soma-se a isso, a relevância de um monitoramento contínuo dos recursos hidrográficos, por parte das agências regulatórias e de captação de água nos Estados, abrangendo um maior conjunto de pontos amostrais. Somente com séries históricas mais consistentes, tanto em escala temporal quanto espacial, será possível o efetivo controle da qualidade hídrica nesse bioma, assim como uma melhor comparação entre diferentes bacias hidrográficas.

\section{AGRADECIMENTOS}

Os autores agradecem à Universidade Federal de Goiás (UFG), por intermédio do Instituto de Estudos s Socioambientais (IESA)/Laboratório de Processamento de Imagens e Geoprocessamento (LAPIG) e à Empresa Brasileira de Pesquisa Agropecuária (Embrapa) pelo suporte técnico a esta pesquisa. Estendemos nossos agradecimentos à Agência Ambiental de Goiás, na pessoa do Sr. Eurivan Alves Mendonça, pela disponibilização dos dados de monitoramento da água. O primeiro autor é bolsista (nível mestrado) da Coordenação de Aperfeiçoamento de Pessoal de Nível Superior (CAPES).

\section{REFERÊNCIAS}

AGÊNCIA AMBIENTAL DE GOIÁS. Monitoramento da água. Disponível em: <http://www.agenciaambiental.go.gov.br/>. Acesso em: 18 dez. 2008. 
RABElo, C. G.; FERreirA, M. E.; ARAúJo, J. V. G.; STONE, L. F.; Silva, S. C.; GOMES, M. P. Influência do uso do solo na qualidade da água no bioma Cerrado: um estudo comparativo entre bacias hidrográficas no Estado de Goiás, Brasil. Ambi-Agua, Taubaté, v. 4, n. 2, p. 172-187, 2009. (doi:10.4136/ambiagua.96)

AGÊNCIA RURAL DE GOIÁS. Geoprocessamento: mapas interativos. Disponível em: $<$ https://intra2.agenciarural.go.gov.br/geonet/mapa/index.php?mapa=goias.php>. Acesso em: 20 dez. 2008.

BONNET, B.; FERREIRA, L. G.; LOBO, F. C. Relações entre qualidade da água e uso do solo em Goiás: uma análise à escala da bacia hidrográfica. Revista Árvore, v. 32, n. 2, p. 311-322, 2008.

BRASIL. Ministério do Meio Ambiente. Conselho Nacional Do Meio Ambiente - CONAMA. Resolução $\mathbf{N}^{\mathbf{0}}$ 357/2005. Disponível em: <http://www.mma.gov.br/port/conama/ legiabre.cfm?codlegi=459>. Acesso em 10 jan. 2009.

CHOMITZ, K. M. Transferable development rights and forest protection: an exploratory analysis. International Regional Science Review, v. 27, n. 3, p. 348-373, 2004.

COMPANHIA DE TECNOLOGIA DE SANEAMENTO AMBIENTAL DO ESTADO DE SÃO PAULO (CETESB). Índice de qualidade da água. Disponível em: < http://www.cetesb.sp.gov.br/Agua/rios/indice_iap_iqa.asp>. Acesso em 06 jan. 2009.

EARTH SCIENCE DATA INTERFACE (ESDI). Disponível em: <http://glcfapp.umiacs.umd. edu:8080/esdi/index.jsp>. Acesso em 19 dez. 2008.

EMPRESA BRASILEIRA DE PESQUISA AGROPECUÁRIA - EMBRAPA Monitoramento por Satélite. Brasil em Relevo. Disponível em: <http://www.relevobr.cnpm.embrapa. br>. Acesso em: 10 fev. 2009.

FERREIRA, M. E.; FERREIRA JR., L. G.; PECCININI, A. A.; HUETE, A. R. Análise Comparativa dos Produtos MODIS Ecologia para o Monitoramento Biofísico Ambiental do Bioma Cerrado. Revista Brasileira de Geofísica, v. 24, p. 251-260, 2006.

FERREIRA, M. E.; MIZIARA, F.; FERREIRA JR., L. G.; RIBEIRO, F. L.; FERREIRA, N. C. Ativos ambientais do bioma Cerrado: uma análise da cobertura vegetal nativa e sua relação com o preço da terra no Estado de Goiás. Revista Brasileira de Cartografia, n. 61, p. 37-50, 2009.

GUERRA, A. J. T. A contribuição da geomorfologia no estudo dos recursos hídricos. Bahia Análise \& Dados, Salvador, v. 13, n. esp., p. 385-389, 2003. Disponível em: <http://www.bvsde.paho.org/bvsacd/cd17/cogeomorf.pdf>. Acesso em: 15 jan. 2009.

IGLIORI, D. C.; SILVA JÚNIOR, D.; LOBO, F. C. Uso de instrumentos econômicos para a proteção de vegetação nativa no Estado de Goiás: uma análise exploratória. Boletim Goiano de Geografia, v. 27, n. 1, p. 63-81, 2007.

LATRUBESSE, E. M.; CARVAlhO, T. M. de.; STEVAUX, J. C. (Coord.) Mapa geomorfológico do Estado de Goiás. Relatório Final. Secretaria de Indústria e Comércio. Superintendência de Geologia e Mineração. Goiânia, 2005. Disponível em: <http://www.sieg.go.gov.br>. Acesso em: 20 jan. 2009.

MIZIARA, F.; FERREIRA, N. C. Expansão da fronteira agrícola e evolução da ocupação e uso do espaço no Estado de Goiás: subsídios à política ambiental. In: Ferreira JÚNIOR, L. G. (Org.). A encruzilhada socioambiental - biodiversidade, economia e sustentabilidade no cerrado. Goiânia: UFG, 2008. p. 107-125. 
RABElo, C. G.; FERreirA, M. E.; ARAúJo, J. V. G.; STONE, L. F.; Silva, S. C.; GOMES, M. P. Influência do uso do solo na qualidade da água no bioma Cerrado: um estudo comparativo entre bacias hidrográficas no Estado de Goiás, Brasil. Ambi-Agua, Taubaté, v. 4, n. 2, p. 172-187, 2009. (doi:10.4136/ambiagua.96)

MORAES, J. C. de. Um modelo hidrometeorológico para bacias hidrográficas de meio porte. 1979. 144f. Dissertação (Mestrado em Meteorologia) - INPE, São José dos Campos, 1979. Disponível em: <http://mtc-m17.sid.inpe.br/col/sid.inpe.br/jeferson/ 2005/06.21.18.04/doc/publicacao.pdf>. Acesso em: 20 jul. 2009.

MYERS, N.; Mittermeier, R. A.; Mittermeier, C. G.; FONSECA, G. A. B. da.; KENT, J. Biodiversity hotspots for conservation priorities. Nature, v. 403, p. 853-858, 2000. Disponível em: <http://www.nature.com/nature/journal/v403/n6772/pdf/403853a0.pdf>. Acesso em 05 dez. 2008.

NEDER, H. D.; SILVA, J. L. M. Pobreza e distribuição de renda em áreas rurais: uma abordagem de inferência. Revista de Economia e Sociologia Rural, v. 42, n. 3, p. 469486, 2004.

NOVAES, P. C.; LOBO, F. C.; FERREIRA, M. E. Pobreza, desenvolvimento e conservação da biodiversidade em Goiás. In: FERREIRA JR., L. G. (Org.). A encruzilhada socioambiental: biodiversidade, economia e sustentabilidade no Cerrado. Goiânia: UFG, 2008. p. 127-149

PROJETO DE CONSERVAÇÃO E UTILIZAÇÃO SUSTENTÁVEL DA DIVERSIDADE BIOLÓGICA BRASILEIRA (PROBIO). Disponível em: <http://mapas.mma.gov.br/ mapas/aplic/probio/datadownload.htm?/>. Acesso em: 21 dez. 2008.

SANO, E. E.; ROSA, R.; BRITO J. L.; FERREIRA JÚNIOR, L. G. Mapeamento semidetalhado (escala de 1:250.000) da cobertura vegetal antrópica do bioma Cerrado. Pesquisa Agropecuária Brasileira, v. 43, n. 1, p. 153-156, 2008a.

SANO, E. E.; DAMBRÓS, L. A.; OLIVEIRA, R. S. B; BRITES, R. S. Padrões de cobertura de solos do Estado de Goiás. In: FERREIRA JR., L. G (Org.). A encruzilhada socioambiental: biodiversidade, economia e sustentabilidade no cerrado. Goiânia: UFG, 2008b. p. 91-106.

SECRETARIA DO PLANEJAMENTO E DESENVOLVIMENTO DO ESTADO DE GOIÁS - SEPLAN/GO. Superintendência de Estatística, Pesquisa e Informação. Estatísticas Municipais. Disponível em: <http://www.seplan.go.gov.br/sepin/perfilweb/conperfil.asp>. Acesso em: 10 abr. 2009.

SISTEMA ESTADUAL DE ESTATÍSTICA E DE INFORMAÇÕES GEOGRÁFICAS DE GOIÁS (SIEG). Download Shapefiles (SIG). Disponível em: <http://www.sieg.go.gov. br>. Acesso em: 20 dez. 2008.

TUNDISI, J. G.; TUNDISI, T. M. A Água. São Paulo: PUBLIFOLHA, 2005. 128p. (Série Folha Explica).

VON SPERLING, M. Introdução à qualidade das águas e ao tratamento de esgotos. 3. ed. Belo Horizonte: UFMG, 2005. 452p. 